\title{
SIMULATIONS OF HEAT TRANSFER THROUGH MULTILAYER PROTECTIVE CLOTHING EXPOSED TO FLAME
}

\author{
Adam K. Puszkarz*, Waldemar Machnowski \\ Institute of Material Science of Textiles and Polymer Composites, Lodz University of Technology, 116 Zeromskiego Street, 90-924 Lodz, Poland \\ ${ }^{*}$ Corresponding author. E-mail: adam.puszkarz@p.lodz.pl
}

\begin{abstract}
:
In this paper, the safety and thermal comfort of protective clothing used by firefighters was analyzed. Threedimensional geometry and morphology models of real multilayer assemblies used in thermal protective clothing were mapped by selected Computer-Aided Design (CAD) software. In the designed assembly models, different scales of the resolution were used for the particular layers - a homogenization for nonwoven fabrics model and designing the geometry of the individual yarns in the model of woven fabrics. Then, the finite volume method to simulate heat transfer through the assemblies caused by their exposure to the flame was applied. Finally, the simulation results with experimental measurements conducted according to the EN ISO 9151 were compared. Based on both the experimental and simulation results, parameters describing the tested clothing protective features directly affecting the firefighter's safety were determined. As a result of the experiment and simulations, comparable values of these parameters were determined, which could show that used methods are an efficient tool in studying the thermal properties of multilayer protective clothing.
\end{abstract}

\section{Keywords:}

Heat transfer; protective clothing; modeling; simulations; the finite volume method; flame; heat radiation

\section{Introduction}

The problem of thermal comfort is inextricably linked to the issue of heat balance between the human body and its environment. The human body continuously exchanges heat with the surrounding environment. This exchange occurs via four different phenomena: conduction, convection, radiation, and sweat evaporation. Each phenomenon is conditioned on the characteristics of the human body including metabolism, temperature, sweat rate, breathing rate, as well as the environment described in terms of air temperature, heat radiation, relative humidity, and velocity of airflow.

Clothing is an essential factor playing a significant role in the heat balance because it creates a barrier between the human body and its environment. In hot environments, clothing protects against excessive heat and help thermoregulatory mechanisms by producing an artificial microclimate next to the human body. These usages are crucial to firefighters, heavy industry workers (ironworks employees), rescuers, and special forces soldiers. Because during their professional activities they may be exposed to flame and the thermal radiation and because of this, their clothing should be designed to protect them against thermal hazards and prevent skin burn.

There are several types of flame-retardant treated fabrics (cotton FR and viscose FR) and fabrics made from inherently flame resistant fibers (aramid, PBI). Protective clothing made from such fabrics does not ignite due to contact with the flame.
However, during various professional activities, the heat flux intensity in the surroundings may even exceed $60-200 \mathrm{~kW} \cdot \mathrm{m}^{-2}$ [1]. These numbers imply that the thermal protective clothing should be evaluated not only for protection against flame but also against heat flux that often results in skin burns.

The heat transfer through protective clothing depends on many factors, such as the geometry of the textiles (thickness, porosity, mutual positions of layers, and fiber number in a yarn cross-section) and the thermal properties of raw materials (specific heat, thermal conductivity, and emissivity). The thermal protection features of multilayer protective clothing are tested following EN ISO 9151 [2] (flame exposure) and EN ISO 6942 [3] (radiation exposure). These standards provide two metrics that are critical for evaluating the protective properties of clothing against thermal hazards [2, 3]. The first metric describes the amount of time needed for the temperature of the inner side of clothing to increase by $12^{\circ} \mathrm{C}$. This temperature increase is assumed to be a pain threshold for users. The second metric describes the amount of time needed for the temperature of the inner side of clothing to increase by $24^{\circ} \mathrm{C}$. When crossing this temperature threshold indicates that the user experienced second-degree burns.

The test methods presented in EN ISO 6942 and EN ISO 9151 are based on the measurement of the temperature change in the copper calorimeter. The main part of the calorimeter is a copper plate as a sensor placed right behind a clothing specimen, which is exposed to heat flux. However, the thermal 
properties of the copper plate, such as heat conductance or thermal capacity, deviate considerably from the human skin. This means that the results of testing the thermal protective properties of clothing obtained by this method may not reflect real situations. For this reason, Keltner [4] suggested replacing the calorimeter with a thermal skin simulant sensor.

Many studies have been undertaken to develop new materials for the manufacturing of protective clothing as well as to create heat transfer models for the prediction of their thermal properties [5-9]. One such model was proposed by Torvi [10] for textiles under high heat flux conditions. Song et al. [11] presented a numerical model of heat and moisture transfer through multilayer protective clothing during exposure to a flash fire. The model predictions were compared with experimental outcomes from various textiles systems.

Nowadays, numerical simulations are effective and widely applied in tools to study thermal processes occurring in thermal protective clothing. The simulations are performed on real clothing models and apply the numerical analysis of physical phenomena to predict the properties of the clothing. Currently, the numerical simulations are a supplement of typical traditional experiments with actual materials [12-18]. The goal of the research presented by Onofrei et al. [14] was to create a heat transfer model in the firefighter's garments exposed to heat radiation. Zhu and Zhou [16] developed a model for moisture and heat exchange through a firefighter's protective clothing when exposed to heat radiation.

The presented work is a continuation of research on modeling physical phenomena that occurred in textiles [19-21]. However, mentioned studies concerned the modeling of thermal phenomena in solids under steady-state conditions. In the current paper, the CAD software to predict heat transfer in textile assemblies intended for thermal protective clothing when exposed to the flame was used. The 3D models of the two actual multilayer assemblies were designed. Different scales of mapping were used, ranging from a homogenization in nonwoven models to mapping of real geometry of the yarns in woven fabrics models. Next, the computational fluid dynamics to model heat transfer induced by flame through multilayer clothing under transient state conditions was used. Finally, the utility of the models through comparisons with experimental outcomes was verified.

\section{Experimental}

\subsection{Materials}

Two multilayer assemblies used in thermal protective clothing were studied (Figure 1). The assemblies consisted of five layers: $A$ - outer shell (woven fabric), $B$ - moisture barrier (membrane), $C$ - nonwoven fabric, $D$ - nonwoven fabric, and $E$ - lining (woven fabric). In both assemblies, Layer $B$ was laminated with Layer $C$, while in the Assembly 2 Layer $D$ was laminated with Layer $E$.
Characteristics of multilayer assemblies were presented in Table 1.

Total porosity $P$ were determined according to Eq (1) [22].

$P=\left(1-\frac{M_{p} \cdot 10^{-3}}{d \cdot \rho}\right) \cdot 100 \%$

where: $M_{p}$ - mass per unit area in $\mathrm{g} \cdot \mathrm{m}^{-2}, d$ - thickness in $\mathrm{mm}$, and $\rho$ - density of the raw material in $\mathrm{g} \cdot \mathrm{cm}^{-3}$. Total porosity $P$ of woven fabrics (Layers $A$ and $E$ ) resulted from porosity of the yarn $P_{\text {yarn }}$ and the free spaces between the yarns from which these fabrics are formed. $P_{\text {yarn }}$ was determined by analyzing the SEM images of the yarn cross-section using Image $J$ software.

All five layers are built of flame-resistant materials but play different roles. Layer $A$ protects against mechanical wear and tear. Layer $B$ (membrane) does not allow water to enter, however, being vapor permeable, it provides air and water vapor (sweat) exchange between the skin and the environment. Layers $C$ and $D$ are the thermal insulations, while Layer $E$ is the lining.

\subsection{Test apparatus and method}

The heat transfer through the multilayer clothing caused by exposure to flame in a transient state was investigated. The tested samples were conditioned in an atmosphere with relative humidity $(R H)$ of $65 \%$ and a temperature of $20^{\circ} \mathrm{C}$ before testing for at least $24 \mathrm{~h}$. The studies were carried out using the test apparatus according to EN ISO 9151, under conditions as follows: air temperature of $20^{\circ} \mathrm{C}$ and $R H$ of $40 \%$. Figure 2 illustrates the experimental setup.

The measuring system consisted of a Meker gas burner, a copper disc calorimeter, a thermometer, and a PC with dedicated software. During the measurement, a horizontally oriented test sample is subjected to an incident heat flux induced by the flame of a gas burner located under it. The heat falls to the outer surface of the tested sample (Layer $A$ ) and passing through other layers of assembly is measured by the calorimeter
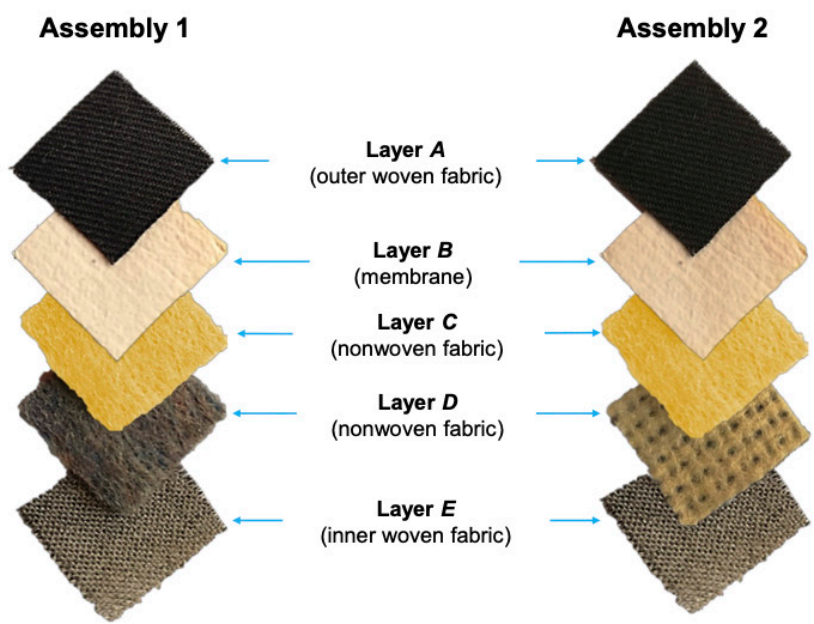

Figure 1. Multilayer assemblies used in the research. 
Table 1. Characteristics of five layers of tested assemblies

\begin{tabular}{|c|c|c|c|c|c|c|c|}
\hline Assembly & Layer name & Layer type & Material & $\begin{array}{c}\text { Thickness, } \\
d[\mu \mathrm{m}]\end{array}$ & $\begin{array}{l}\text { Mass per } \\
\text { unit area, } \\
M_{p}\left[\mathrm{~g} \cdot \mathrm{m}^{-2}\right]\end{array}$ & $\begin{array}{c}\text { Total } \\
\text { porosity, } \\
P[\%]\end{array}$ & $\begin{array}{c}\text { Yarn } \\
\text { porosity } \\
P_{\text {yarn }}[\%]\end{array}$ \\
\hline \multirow{5}{*}{1} & $A$ & Outer woven fabric & Aramid & 420 & 210 & 63 & 43 \\
\hline & $B$ & Membrane & Polyurethane & 20 & \multirow{2}{*}{$115^{*}$} & \multirow{2}{*}{$84^{*}$} & \multirow{2}{*}{-} \\
\hline & C & Nonwoven fabric & Aramid & 500 & & & \\
\hline & $D$ & Nonwoven fabric & Aramid & 1,620 & 155 & 93 & - \\
\hline & $E$ & Inner woven fabric & Aramid & 310 & 125 & 70 & 42 \\
\hline \multirow{5}{*}{2} & $A$ & Outer woven fabric & Aramid & 420 & 210 & 63 & 43 \\
\hline & $B$ & Membrane & Polyurethane & 20 & \multirow{2}{*}{$115^{*}$} & \multirow{2}{*}{$84^{*}$} & \multirow{2}{*}{-} \\
\hline & C & Nonwoven fabric & Aramid & 500 & & & \\
\hline & $D$ & Nonwoven fabric & Aramid & 750 & 60 & 94 & - \\
\hline & $E$ & Inner woven fabric & Aramid & 310 & 125 & 70 & 42 \\
\hline
\end{tabular}

*Layers B and C are permanently connected.

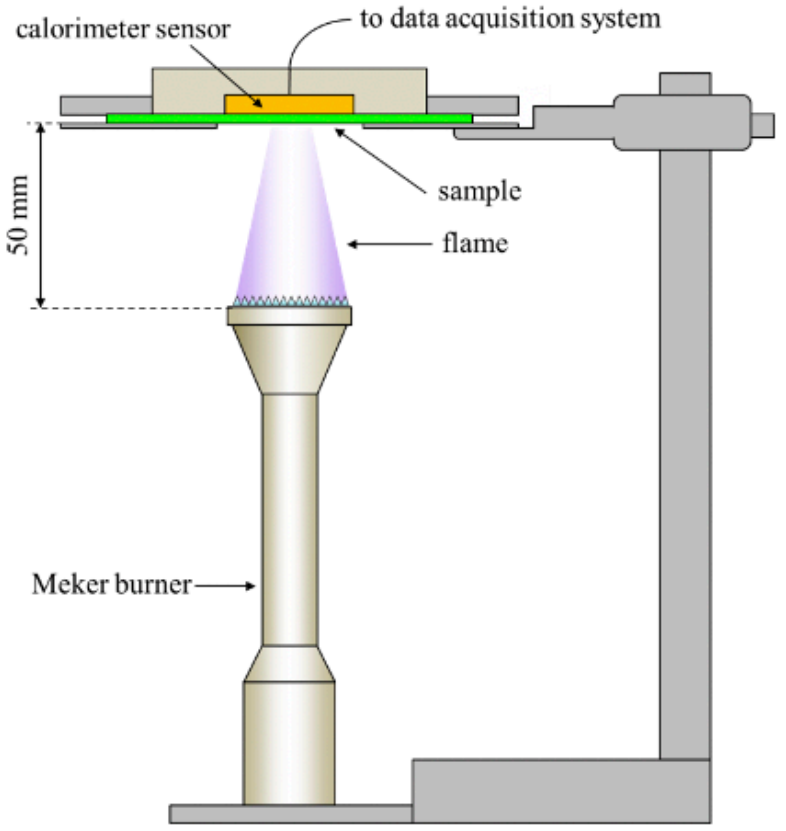

Figure 2. Schematic of the experimental setup used for the test.

having direct contact with Layer $E$. The calorimeter was linked to a digital, computer-driven thermometer, which records the growth of Layer $E$ temperature in time. Measurements of the temperature of the inner surface of the sample (Layer $E$ ) were recorded in 1 second intervals until the temperature of the Layer $E$ increased to $50^{\circ} \mathrm{C}$. The measurements were carried out for two intensity levels of incident heat flux: $45 \mathrm{~kW} \cdot \mathrm{m}^{-2}$ and $58 \mathrm{~kW} \cdot \mathrm{m}^{-2}$. The final results of these tests were the average values of three individual tests made for each of the two above mentioned intensity levels of heat flux. Based on the experiment, following thermal parameters were determined:

- heat transfer index $\left(\mathrm{HTI}_{12}\right.$ and $\left.\mathrm{HTI}_{24}\right)$ means time to achieve a temperature rise of $12^{\circ} \mathrm{C}$ and $24^{\circ} \mathrm{C}$, respectively, in the calorimeter, when a specified heat flux acts on the sample.

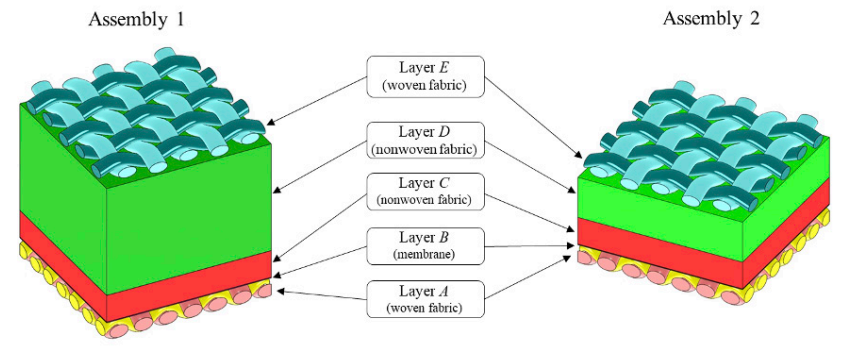

Figure 3. Models of two tested multilayer assemblies.

- heat transmission factor (HTF) is numerically equal to the ratio of the transmitted heat flux density to the incident heat flux density.

\section{Modeling}

\subsection{Model design}

In the designed 3D models of two tested assemblies (Figure 3 ) both woven fabrics (Layers $A$ and $E$ ) were mapped with the following parameters: (1) layer thickness, (2) distance between yarns, and (3) elliptic cross-section of yarns.

In the designed models, each layer was designed separately, and then the layers were combined into the final assembly. In the designed models, the layers lie on top of each other in direct contact (no air gap). The model does not take into account sewing threads connecting layers due to its negligible low weight and negligibly low impact on heat transfer inside the assembly.

Both nonwovens (Layers $C$ and $D$ ), membrane (Layer $B$ ) and yarn in both woven fabrics (Layers $A$ and $E$ ) due to their complex internal structure, were designed as the homogenized three- 
dimensional objects with physical features (density, thermal conductivity, and specific heat) resulting from corresponding porosity showed in Table 1. Table 2 presents the basic physical parameters of the materials from which the tested assemblies are made $[23,24]$.

\subsection{Simulations}

\subsubsection{Physical basis of heat flow simulation}

The finite volume method was carried out using Solidworks Flow Simulation 2014 software to analyze the heat transfer through the tested assembly. The software allows to predict fluid flow solving energy conservation equations and NavierStokes formulas [18] and allows estimating simultaneous heat transfer in solid, liquid, and gaseous states and incorporates energy exchange between these states. The above-mentioned equations are augmented by fluid state equations and by empirical dependence of fluid density, viscosity, and thermal conductivity on temperature. The software allows to analyze following physical phenomena: (1) heat transfer in solids (conduction), (2) free, forced, and mixed convection, and (3) radiation both in the steady-state and transient state [25]. A broader description of the physical laws based on which the simulations were carried out was presented in earlier work on modeling of thermal performance of multilayer protective clothing exposed to radiant heat [22].

\subsubsection{Conditions of heat flow simulations}

The main aim of the heat transfer simulations was to determine the time dependence of the temperature of Layer $E$ of the two assembles models for two intensity levels of heat flux which were used in the experimental measurements. For this purpose, the assembly model was placed inside a rectangular computational domain filled with air (presented in Figure 4). To model the effect of the flame from the Meker burner, a heat flux of the values used in the experiment $\left(45 \mathrm{~kW} \cdot \mathrm{m}^{-2}\right.$ or $58 \mathrm{~kW} \cdot \mathrm{m}^{-2}$ ) was applied to the lower surface of Layer $A$ of the model of the tested assembly. Initial ambient conditions within the computational domain were consistent with the initial conditions of the experiment i.e.: $T_{\text {air }}=20^{\circ} \mathrm{C}, p_{\text {air }}=1,013.25 \mathrm{hPa}$, $T_{\text {model }}=20^{\circ} \mathrm{C}, R H=40 \%$. To eliminate asymmetric boundary conditions, settings were used to imitate an infinite five layers of assembly propagating outside of the computational domain in all four horizontal directions.

Before starting the simulations, the computational domain containing the assembly model was filled with a finite volume mesh divided into 172,338 fluid cells, 252,313 solid cells and

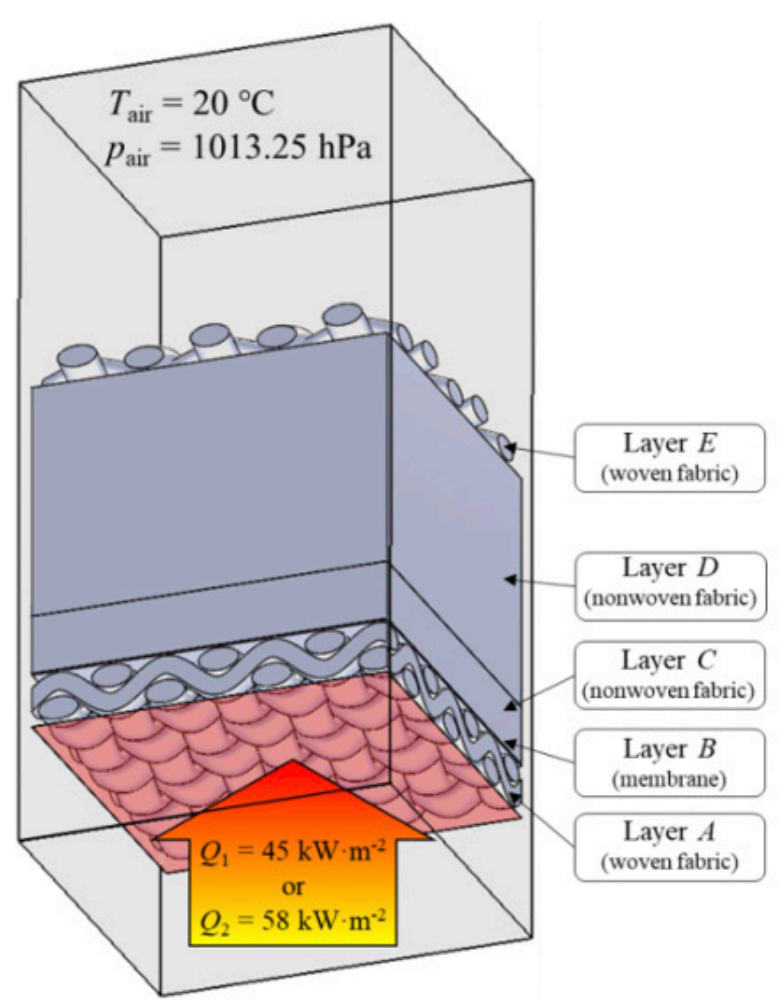

Figure 4. Model of assembly located inside the computational domain. Initial ambient conditions of simulation: $T_{\text {air }}=20^{\circ} \mathrm{C}, p_{\text {air }}=1,013.25 \mathrm{hPa}$, $T_{\text {model }}=20^{\circ} \mathrm{C}, R H=40 \%$. The heat flux incident on Layer $A: 45 \mathrm{~kW} \cdot \mathrm{m}^{-2}$ or $58 \mathrm{~kW} \cdot \mathrm{m}^{-2}$.

206,231 partial cells for Assembly 1 and 93,306 fluid cells, 129,680 solid cells and 124,438 partial cells for Assembly 2 .

\section{Results and discussion}

In Figures 5 and 6, a comparison between the experimental and the simulated results was presented. It shows a pronounced relationship between the temperature of the inner surface of tested assemblies and the intensity level of heat flux directed to the outer surface of the sample.

Both experimental and simulated results obtained for tested levels of heat flux density show that the temperature rise process of Layer $E$ could be imparted into two stages. The first stage takes about 3-5 s. During the stage, the temperature of Layer $E$ remains almost unchanged. This could be caused by the multilayer, porous sample structure, the thermal capacity of the sample, and the thermal inertia of the calorimeter used. The inertia could influence the precision of temperature measurements of the sample. During the second phase of the

Table 2. Physical features of raw materials used in simulations

\begin{tabular}{|c|c|c|}
\hline Physical parameter & Aramid & Polyurethane \\
\hline Density $\left[\mathrm{kg} \cdot \mathrm{m}^{-3}\right]$ & 1,360 & 1,260 \\
\hline Specific heat $\left[\mathrm{J} \cdot \mathrm{kg}^{-1 .}{ }^{\circ} \mathrm{C}^{-1}\right]$ & 1,390 & 0.23 \\
\hline Thermal conductivity $\left[\mathrm{W} \cdot \mathrm{m}^{-1} \cdot{ }^{\circ} \mathrm{C}^{-1}\right]$ & 0.18 & 0.90 \\
\hline Emissivity $($ for black body $=1$ ) & 0.92 & 0 \\
\hline
\end{tabular}




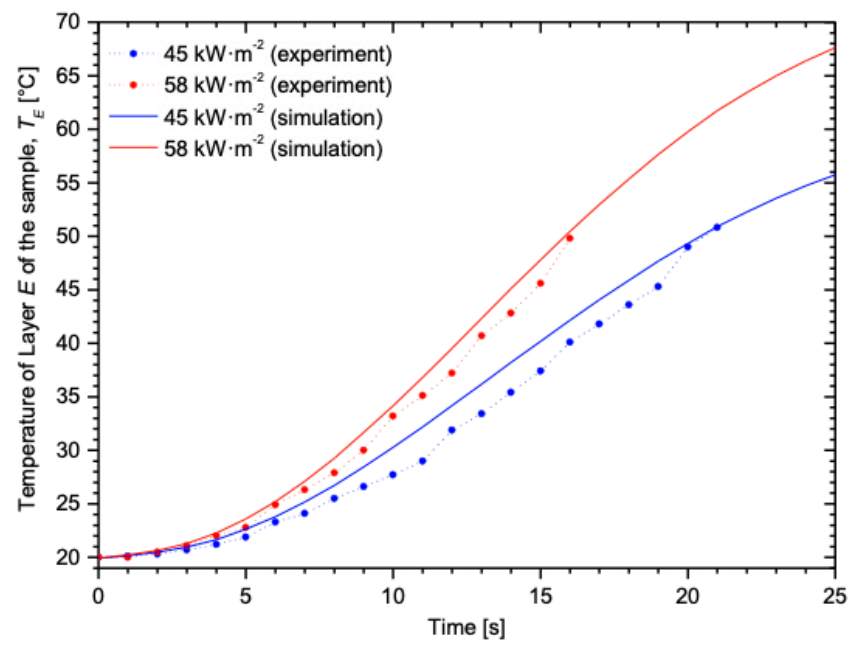

Figure 5. Dependence of temperature of sample inner surface on time of sample outer surface exposure to flame: Assembly 1 (dots experiment, solid line - simulation).

temperature rise, the temperature of the sample inner surface (Layer $E$ ) is approximately in a linear time dependence with the slope proportional to the heating rate of the sample. One can see that for both the tested intensity levels of heat flux, the modeled heating rate of the sample model consistently overestimated the heating rate of the real sample during experimental measurements. The slope of the temperature versus time modeled curves is higher than the slope of the curves obtained experimentally. The thermal parameters obtained in the experiment and by simulation for two tested assemblies were presented in Table 3.

Relative disagreements between experimental and modeled parameter estimates depended on the intensity level of heat flux, they are: $8-13 \%$ for $\mathrm{HTI}_{12}, 0-6 \%$ for $\mathrm{HTI}_{24}$, and $0-19 \%$ for HTF. The comparative analysis of the simulated and experimental values of these parameters revealed the biggest compatibility between the outcomes in the case of $\mathrm{HTI}_{24}$ (Assembly 2, $Q=58 \mathrm{~kW} \cdot \mathrm{m}^{-2}$ ), however, the smallest one in the case of HTF (Assembly 1, Q $=58 \mathrm{~kW} \cdot \mathrm{m}^{-2}$ ). As expected, the $\mathrm{HTI}_{24}$ value that expresses the time of the clothing exposure to heat flux at which second-degree burns may occur, decreases with an increase in the intensity level of heat flux directed to the sample. In Figures 7 and 8, the temperature distribution on the surface of the $3 \mathrm{D}$ model of the multilayer protective clothing

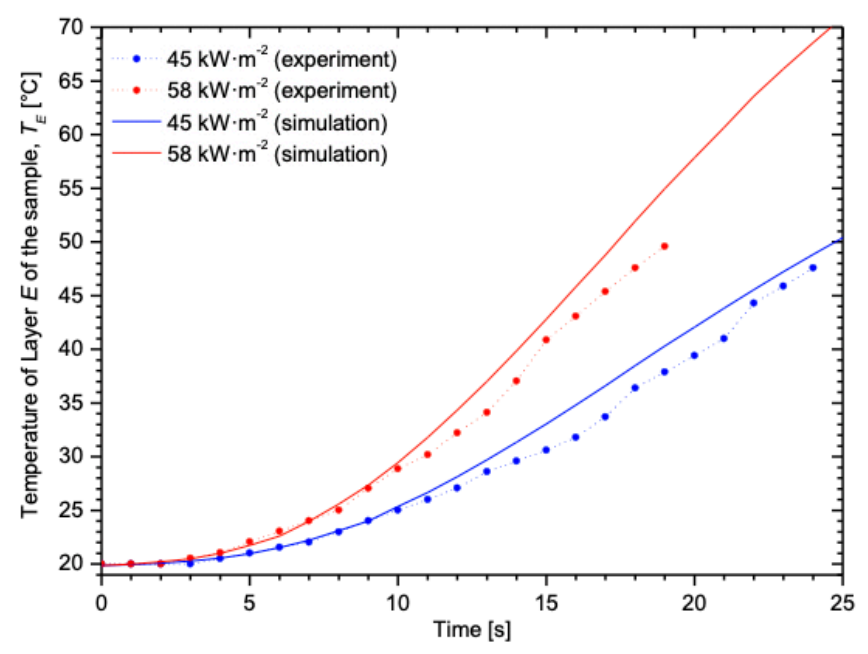

Figure 6. Dependence of temperature of sample inner surface on time of sample outer surface exposure to flame: Assembly 2 (dots experiment, solid line - simulation).

calculated for six selected periods of exposure to heat flux density of $58 \mathrm{~kW} \cdot \mathrm{m}^{-2}$ was presented.

\section{Conclusions}

In this paper, the outcomes of the modeling of the two textile assemblies intended for multilayer protective clothing to calculate the heat transport through the assembly caused by flame were obtained using the computational fluid dynamics (CFD). Two assembly models built of five layers consisting of two woven fabrics, two nonwoven fabrics, and membrane, were designed. The models assumed the simplifications regarding both geometry and the internal structure of individual layers. The model has been validated by experiment results performed according to EN ISO 9151. Simulations carried out on both models gave results that correlated with experimental curves describing the relationship between the temperature of lining and outer shell exposure time to heat flux generated by gas Meker burner. The two parameters of protective clothing (HTI and HTF) were determined experimentally and by simulation. The experimental results are compatible with simulated predictions and the dissimilarity between them depends on the specific parameter and the applied incident heat flux density. These differences could be related to the main difficulty

Table 3. Thermal protective parameters of tested assemblies determined experimentally and by simulations

\begin{tabular}{|c|c|c|c|c|c|c|}
\hline \multirow{2}{*}{$\begin{array}{l}\text { Incident heat } \\
\text { flux, } Q\left[\mathrm{~kW} \cdot \mathrm{m}^{-2}\right]\end{array}$} & \multicolumn{2}{|c|}{$\mathrm{HTI}_{12}[\mathrm{~s}]$} & \multicolumn{2}{|c|}{$\mathrm{HTI}_{24}$ [s] } & \multicolumn{2}{|c|}{ HTF } \\
\hline & Experiment & Simulation & Experiment & Simulation & Experiment & Simulation \\
\hline \multicolumn{7}{|c|}{ Assembly 1} \\
\hline 45 & 16 & 14 & 22 & 21 & 0.20 & 0.20 \\
\hline 58 & 12 & 11 & 16 & 15 & 0.21 & 0.25 \\
\hline \multicolumn{7}{|c|}{ Assembly 2} \\
\hline 45 & 12 & 11 & 18 & 17 & 0.24 & 0.23 \\
\hline 58 & 10 & 9 & 14 & 14 & 0.24 & 0.25 \\
\hline
\end{tabular}



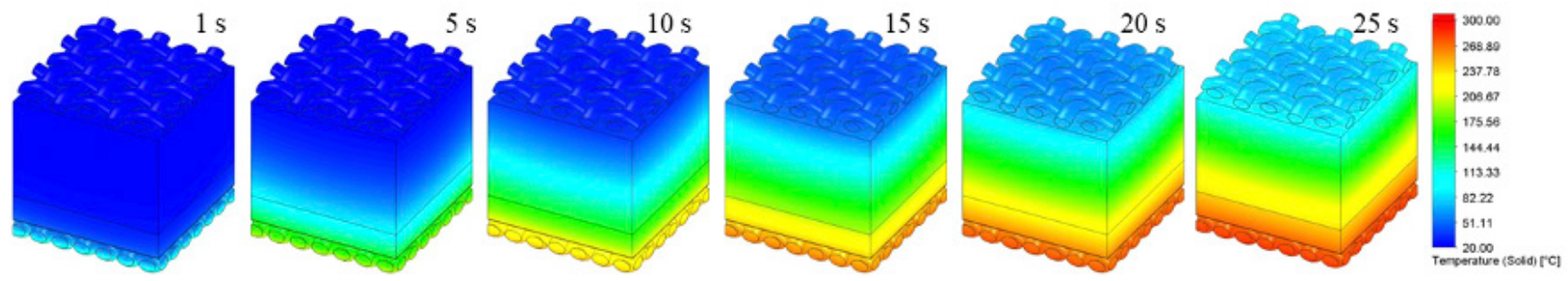

Figure 7. Visualization of temperature growth in the time of Assembly 1 model (heat flux density of $58 \mathrm{~kW} \cdot \mathrm{m}^{-2}$ ).
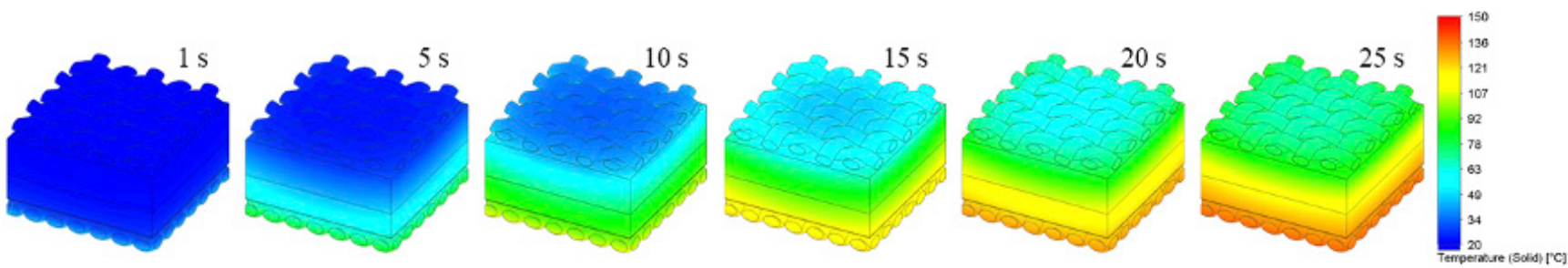

Figure 8. Visualization of temperature growth in the time of Assembly 2 model (heat flux density of $58 \mathrm{~kW} \cdot \mathrm{m}^{-2}$ ).

of textiles modeling (referring to above all simplification concerning the complicated geometry of real textiles) like:

- Homogenization (fibers with air) instead of mapping in the models the single fibers and free gaps between them,

- In the woven fabrics model, a constant elliptic crosssection of yarn constant-in all repeat was adopted. In the real woven fabrics, the shape of the cross-section of yarn changes constantly due to frictional forces between warp and weft, and

- Real direct contact of the nearest layers (influencing the interlayer thermal conductivity) may be different in the model than in the actual multilayer textile assembly.

Despite the simplifications mentioned above, the designed 3D models of multilayer assemblies and performed simulations allow to:

- predict parameters characterizing protective clothing with an error of $0-16 \%$ (Assembly 1 ) and with an error of $0-10 \%$ (Assembly 2),

- understand the phenomenon of heat transfer through multilayer textile structures, and

- optimize the thermal protection properties of protective clothing.

\section{Acknowledgments}

These studies were financed from funds assigned from 142/501/14-148-1-19 statutory activity by the Lodz University of Technology, Institute of Material Science of Textiles and Polymer Composites, Poland.

\section{References}

[1] Luo, M. C., Beck, V. (1996). A study of non-flashover and flashover fires in a full-scale multiroom building. Fire Safety Journal, 26(3), 191-219.

[2] EN ISO 9151:2016 (2016). Protective clothing against heat and flame. Determination of heat transmission on exposure to flame.

[3] EN ISO 6942:2002. (2002). Protective clothing. Protection against heat and fire. Method of test: Evaluation of materials and material assemblies when exposed to a source of radiant heat.

[4] Keltner, N. (2005). Evaluation thermal protective performance testing. Journal of ASTM International, 2, 1-14.

[5] Zhang, H., Song, G., Su, H., Ren, H., Cao, J. (2017). An exploration of enhancing thermal protective clothing performance by incorporating aerogel and phase change materials. Fire and Materials, 41, 953-963.

[6] Torvi, D. A., Eng, P., Threlfall, T. G. (2006). Heat transfer model of flame resistant fabrics during cooling after exposure to fire. Fire Technology, 42, 27-48.

[7] Prahsarn, C., Roungpaisan, N., Klinsukhon, W., Suwannamek, N., Padee, S. (2018). Thermal and flame retardant properties of shaped polypropylene fibers containing modified-thai bentonite. AUTEX Research Journal, 18(1), 13-19.

[8] Matusiak, M., Kowalczyk, S. (2014). Thermal-insulation properties of multilayer textile packages. AUTEX Research Journal, 14(4), 299-307. 
[9] Gadeikytè, A., Barauskas, R. (2020). Investigation of influence of forced ventilation through $3 D$ textile on heat exchange properties of the textile layer. Journal of Measurements in Engineering 8(2), 72-78.

[10] Torvi, D. A., Hadjisophocleus, G. V. (1999). Research in protective clothing for firefighters: State of the art and future directions. Fire Technology 35(2), 111-130.

[11] Song, G., Mandal, S., Rossi, R. M. (2017). Thermal protective clothing for firefighters. Woodhead Publishing Series in Textiles: Number 189, Amsterdam.

[12] Zhu, F., Li, K. (2011). Numerical modeling of heat and moisture through wet cotton fabric using the method of chemical thermodynamic law under simulated fire. Fire Technology, 47, 801-819.

[13] Puszkarz, A. K., Krucinska, I. (2018). Simulations of air permeability of multilayer textiles by the computational fluid dynamics. International Journal for Multiscale Computational Engineering, 16(6), 509-526.

[14] Onofrei, E., Petrusic, S., Bedek, G., Dupont, D., Soulat, $D$. (2013). Study of heat transfer through multilayer textile structure used in firefighter protective clothing. 13th AUTEX World Textile Conference, Dresden, Germany.

[15] Fangrat, J., Wolański, P. (1991). One-dimensional analytical model of flame spread over solids. Journal of Fire Sciences, 9(5), 424-437.

[16]Zhu, F. L., Zhou, Y. (2013). Modelling heat moisture transport through firefighters' protective fabrics from an impinging flame jet by simulating the drying process. Fibres and Textiles in Eastern Europe 21, 5(101), 85-90.
[17] Tian, M., Wang, Z., Li, J. (2016). 3D numerical simulation of heat transfer through simplified protective clothing during fire exposure by CFD. International Journal of Heat and Mass Transfer, 93, 314-321.

[18] Angelova, R. A., Kyosov, M., Stankov, P. (2019). Numerical investigation of the heat transfer through woven textiles by the jet system theory. Journal of the Textile Institute, 110(3), 386-395.

[19] Puszkarz, A. K., Krucinska, I. (2016). The study of knitted fabric thermal insulation using thermography and finite volume method. Textile Research Journal, 87(6), 643-656.

[20] Puszkarz, A. K., Krucinska, I. (2016). Study of multilayer clothing thermal insulation using thermography and the finite volume method. Fibres and Textiles in Eastern Europe 24 6(120), 129-137.

[21] Puszkarz, A. K., Usupov, A. (2019). The study of footwear thermal insulation using thermography and finite volume method. International Journal of Thermophysics, 40, 45.

[22] Puszkarz, A. K., Machnowski, W., Błasińska, A. (2020). Modeling of thermal performance of multilayer protective clothing exposed to radiant heat. Heat and Mass Transfer. doi: 10.1007/s00231-020-02820-1.

[23] Polymerdatabase (2020). Web site: http://polymerdatabase. com (accessed 18 May 2019).

[24] The Engineering ToolBox. (2001). Web site: https://www. engineeringtoolbox.com (accessed 18 May 2019).

[25] SolidWorks Flow Simulation - Technical Reference 2014. 